\title{
“Água enquanto...”: estudo das múltiplas performances da água no contexto de escassez hídrica do Distrito Federal ${ }^{1}$
}

\author{
Larissa do Carmo Inácioº \\ Recebido em setembro de 2020 \\ Aceito em dezembro de 2020
}

\begin{abstract}
RESUMO
O propósito deste estudo é inserir a questão hídrica e suas performances nos debates das Ciências Sociais, a partir de sua entrada nos Estudos Sociais de Ciência e Tecnologia (ESCT), tomando como principal eixo teórico as contribuições dos autores e autoras da Pós-Teoria Ator-Rede (Pós-TAR). Buscou-se mapear como as diferentes performances discursivas da água, em torno do recente contexto de escassez hídrica pelo qual o Distrito Federal passou, entre os anos de 2016 e 2018, se distinguiram, quais atores e atoras estiveram envolvidos nessa rede e de quais maneiras essas distinções estão presentes em seus discursos. O objetivo do presente estudo é analisar a arena do conflito hídrico, mobilizado pelo contexto de escassez, como um local de performatização de atores não humanos no mundo social. Conduzidas as análises de conteúdo dos múltiplos atores e atoras sobre a questão, se buscou observar nessas performances discursivas os modos de coordenação e descoordenação que permitem a performatização da água enquanto parte de múltiplas realidades.
\end{abstract}

Palavras-chave: Água; escassez hídrica; performance; teoria ator-rede; pós-TAR.

\section{"Water as...": study of multiple water performances in the context of water scarcity at Distrito Federal}

\begin{abstract}
This paper aims to include water and the way it is performed in debates in the Social Sciences by using approaches from the Social Studies of Science and Technology (SSST), more specifically, contributions from Post-Actor-Network Theory (Post-ANT). To do so, we map out the discursive performances of water during the water scarcity in Distrito Federal, Brazil, in the years of 2016 and 2018, which actors were involved in these performances, and the ways water was performed by each group. By doing so, we examine the conflicts surrounding the water as situations where non-human actors are performed in the social world. By conducting a content analysis of the discourses of a number of diverse actors, we examined how, through mechanisms of coordination and discoordination, water is performed as part of multiple realities.
\end{abstract}

Keywords: Water; water scarcity; performance; post-ANT.

\footnotetext{
${ }^{1}$ Uma versão preliminar do presente trabalho foi apresentada no VIII Simpósio Nacional de Ciência, Tecnologia e Sociedade/VIII ESOCITE.BR e encontra-se disponível no endereço <http://www.esocite8.cefetmg.br/anais-2/.

${ }^{2}$ Mestranda em Sociologia pelo Programa de Pós-Graduação em Sociologia pela Universidade de Brasília (PPGSOL/UnB). Bolsista de mestrado pelo Conselho Nacional de Desenvolvimento Científico e Tecnológico (CNPq). Integrante do Grupo de Pesquisa “Ciências, Tecnologias e Públicos” (CTP/CNPq). E-mail: larissacinacio@gmail.com.
} 
$\mathrm{O}$ termo "água", enquanto objeto das ciências sociais, é polissêmico e responde às circunstâncias ao seu redor (STRANG, 2004; ANAND, 2017). Seja enquanto recurso natural, ferramenta de desenvolvimento econômico, mecanismo estratégico de implementação de políticas ou enquanto mudanças de práticas, o termo mobiliza com ele uma série de aspectos culturais, políticos, sociais e econômicos que, por sua vez, tocam outra série de variáveis ao seu redor. De modo que torna-se difícil dizer "Água é...” e permite que a expressão “Água enquanto...” seja cada vez mais adequada à medida em que se avançará neste trabalho.

O propósito deste estudo é inserir a questão hídrica e suas perspectivas nos debates das ciências sociais a partir de sua entrada nos estudos em ciência, tecnologia e sociedade, com enfoque teórico nas contribuições dos autores e autoras da Pós-Teoria Ator-Rede (Pós-TAR). O recente contexto de escassez hídrica pelo qual passou o Distrito Federal, entre os anos de 2016 e 2018, suscitou o debate sobre como a água pode ser performada a partir dos referenciais ontológicos dos mais distintos atores. Desse modo, buscou-se mapear como algumas das performances discursivas se distinguem, quais os atores envolvidos nessa rede e de quais maneiras essas distinções estão presentes em seus discursos.

O objetivo é observar a arena do conflito hídrico, mobilizado pelo contexto de escassez, como local das práticas de atores não-humanos sendo performadas sobre o mundo social. Em seguida, são discutidos, a partir das contribuições do pós-TAR, os entendimentos da água enquanto prática econômica, científico-tecnológica e vinculadas ao bem-estar humano, e em como realidades específicas são performadas a partir dessas práticas. Os alinhamentos teóricos do trabalho dão seguimento às análises de conteúdo dos discursos de múltiplos atores e atoras sobre a questão. Se busca observar nessas práticas discursivas como os modos de performatizar água e produzir realidades se distinguem e se coordenam continuamente. Para isso, foram examinadas as reportagens da cobertura jornalística da questão hídrica no Distrito Federal no período entre os anos de 2016 e 2018, coincidente com as medidas de contingenciamento implantadas pela Agência Reguladora de águas, Energia e Saneamento do Distrito Federal (Adasa). 
Usando-se da metodologia de análise documental (CRESWELL, 2007), foi feito o levantamento prévio das reportagens nos arquivos dos portais eletrônicos dos periódicos com os termos "racionamento", “crise hídrica” e "Distrito Federal”. A partir das reportagens obtidas, foram selecionadas aquelas que possuíssem como palavraschave os termos "conflito", "soluções" e "desigualdade". Este estudo foi realizado a partir da análise do conteúdo das reportagens jornalísticas selecionadas (CRESWELL, 2007), verificando-se, principalmente, a ocorrência dos termos "prejuízo”, "dependência”, "produção”, "investimento”, “tecnologia”, “fontes de captação”, “desigualdade”, “direito” e "injustiça”.

A partir das análises dos conteúdos encontrados nos discursos dos atores e tendo como aparato teórico a perspectiva de realidades múltiplas produzidas em torno da água, ficaram evidentes alguns pontos de tensão e as condições nas quais são situados os discursos sobre a água. Ainda que a noção de escassez seja comum aos mais diferentes grupos em torno da questão, a água é performada de maneiras também diferentes. A coleta dos dados documentais dos discursos dos atores coloca em questão a noção de que falar sobre água mobilizaria categorias ontológicas, ou seja, realidades possíveis dadas as circunstâncias, diferentes para cada grupo. Argumenta-se aqui que as realidades performadas em torno da água são fluidas e variadas.

\section{Os estudos sociais de ciência e tecnologia e a emergência das abordagens relativistas}

O campo dos Estudos Sociais da Ciência e Tecnologia (ESCT) é uma área que, inicialmente, inspirou-se nos estudos de Émile Durkheim sobre as crenças religiosas e sua relação com o mundo social (DUARTE, 2007). Durkheim afirmava que, sendo as crenças religiosas um reflexo dos fundamentos sociais que organizavam uma sociedade, elas deveriam ser explicadas pela sociologia a partir de fatores sociológicos (DURKHEIM, 1973).

Baseado nisso, o Programa Forte em Sociologia (BLOOR, 1976/2009; BARNES et al., 1996; SHAPIN, 1979) (Bloor, 1976/2009; Barnes et al., 1996; Shapin, 1979), fundado em Edimburgo, na década de 1970, retomou as considerações de Durkheim sobre as 
crenças religiosas, com o objetivo de aplicá-las no estudo do conhecimento científico. Até então, a ciência era objeto da sociologia a partir das normas e valores que orientariam as práticas das cientistas. ${ }^{3}$ Enquanto isso, a natureza desse mesmo conhecimento permanecia livre do escrutínio sociológico. Dessa forma, o Programa Forte se propôs ao exame do conhecimento, entendido aqui como um conjunto de crenças socialmente compartilhadas, assumidas como verdadeiras e coletivamente endossadas (BLOOR, 1976/2009).

A principal contribuição que o Programa Forte traz para a agenda de pesquisa nos ESCT está na análise do conhecimento científico não mais como produto de um processo cognitivo distinto e privilegiado, mas resultante das práticas sociais, permitindo, assim, que se tornasse objeto de análise da sociologia (PREMEBIDA et al., 2011; Duarte e Reyes-Galindo, 2019). O status de verdade atribuído ao conhecimento científico se deveria, portanto, a fatores sociais e não a uma racionalidade universal subjacente à ciência. Desse modo, os processos de consolidação desse conhecimento estariam vinculados aos contextos de negociação, fatores de persuasão, mobilização de interesses e envolveriam variadas dinâmicas sociais de poder (DUARTE E REYESGALINDO, 2019).

Dos anos 1970 em diante, os ESCT experimentaram uma vertiginosa expansão da agenda de pesquisa, com os mais distintos direcionamentos, incluindo: o Programa Empírico-Relativista (COLLINS, 1985/2011), as etnografias de laboratório (KNORRCETINA, 1982; TRAWEEK, 1988; LATOUR E WOOLGAR, 1997), a teoria ator-rede (TAR) (LATOUR, 1994; CALLON, 1986), o estudo das Políticas Ontológicas, ou Pós-TAR (MOL, 2002; LAW, 2004, 2009) e as contribuições feministas (HARDING, 1987; HARAWAY, 1995; SCHIEBINGER, 2001) são apenas alguns exemplos das abordagens que se desenvolveram posteriormente ao Programa Forte.

O presente estudo leva em consideração as contribuições da Teoria Ator-Rede no campo dos estudos em ciência e tecnologia e, principalmente, no campo dos estudos ambientais. Os desenvolvimentos da TAR levaram a um processo de deslocamento do olhar dos pesquisadores e pesquisadoras para objetos, sujeitos e atores que

\footnotetext{
3 Como sugestão de leitura sobre a temática das normas e valores que orientam as práticas das cientistas, ver o estudo de Robert K. Merton “Sociologia: Teoria e Estrutura” (1968).
} 
anteriormente não eram considerados nos processos de reconstrução das narrativas sociais, requerendo uma reconfiguração das relações sociomateriais entre humanos e objetos (MARRES, 2009). Alcadipani e Tureta (2009, p. 648) referem-se à TAR como “[...] ontologicamente relativista, ao considerar que o mundo pode ser organizado de muitas formas diferentes [...]”. Essa característica de relativização da ontologia da TAR surge como uma alternativa para se refletir acerca de questões que já não mais podiam ser contidas nos pressupostos teóricos até então mobilizados pelas ciências sociais.

Se compreendermos esse processo de emergência de agendas, segundo Souza (2015) ao mesmo tempo em que coloca em evidência variáveis que anteriormente não eram consideradas, passamos a recuperar elementos de construção do mundo e da realidade e, por consequência, das relações sociais que se formam nesse emaranhado de atores, objetos e práticas. Nesse sentido, são desenvolvidos estudos posteriores à TAR que focalizam na reflexão acerca dos processos produtores de realidades e organização do mundo, tomando o lugar de idiomas representacionais e abrindo espaço para a emergência da multiplicidade das realidades. A noção de ontologia transforma-se, pois, em elemento fundamental para a compreensão de um mundo - ou vários - povoado pela agencialidade de atores e atoras que escapam às dicotomias humano e não humano, não se limitando a uma compreensão rígida do "social" (MOL, 2002; SOUZA, 2015; LAW 2019).

\subsection{A noção de ontologia no Pós-Teoria Ator-Rede: performando realidades e multiplicando mundos}

Segundo Mol (2002; 2008) entendimento de ontologia refere-se às condições de possibilidades com as quais somos capazes de viver. ${ }^{4} \mathrm{E}$ quando inscrito na esfera da política evidencia o pressuposto de que a realidade não será um elemento predecessor das práticas, mas ao contrário: é através das práticas que a realidade é construída. Mol

\footnotetext{
${ }^{4}$ É importante ressaltar que o posicionamento ontológico ao qual o presente trabalho faz referência é o que Souza (2015) destaca como "empírico". Neste esquema inicialmente proposto por Marres (2009), leva-se em consideração não somente o aspecto teórico através do qual a existência de algumas entidades são postas a prova; mas as multiplicações das realidades estão voltadas para as diferentes práticas e discursos que se constituem e se articulam na produção desses mundos (SOUZA, 2015).
} 
(2008) procura deixar claro que a ontologia se refere ao real, às reais condições de possibilidade com a qual vivemos, que não nos são dadas à partida:

\begin{abstract}
Refere-se a ontologia - que na linguagem filosófica comum define o que pertence ao real, as condições de possibilidade com que vivemos. A combinação dos termos "ontologia" e "política" sugere-nos que as condições de possibilidade não são dadas à partida. Que a realidade não precede as práticas banais nas quais interagimos com ela, antes sendo modelada por essas práticas. O termo política, portanto, permite sublinhar este modo ativo, este processo de modelação, bem como o seu caráter aberto e contestado (MOL, 2008, p. 2).
\end{abstract}

Diferentemente de um perspectivismo ou construtivismo teórico, as realidades performadas através de conjuntos de práticas assentam-se no pressuposto de serem múltiplas (MOL, 2002, 2008), aspirando dar conta de entidades e processos que antes se encontravam à margem dos estudos sociológicos. Não ocorre aqui a multiplicidade de olhares ou a criação de um olhar específico; ao contrário, multiplicam-se os mundos através das mais diferentes práticas que os constroem (LAW, 2019; MOL, 2008). Realidades não são construtos ou meros dados observáveis, mas se formam a partir dos entendimentos e das práticas cotidianas (LAW e MOL, 1995).

Contribuições posteriores ao desenvolvimento da TAR, como as apresentadas por Annemarie Mol (2002, 2008), Noortje Marres (2009), Casper Bruun Jansen (2004) e John Law (2004), envolvem, primeiramente, um exercício que Souza (2015) define como uma "virada ontológica", através da qual rejeita-se as abordagens epistemológicas representacionais e a própria concepção de ciência como uma esfera bem delimitada, autônoma e universalista. Rejeita-se da mesma maneira o pressuposto de que as relações da ciência com a política, por exemplo, se dariam a partir de pontos de contato específicos, cada uma preservando as características que lhe são distintivas, sem nunca se misturarem de fato. Ao mesmo tempo, as perspectivas do pós-TAR assumem como pressuposto fundamental a noção que no mundo coexistem as mais variadas formas de agencialidade, não estando estas restritas à seara dos humanos. Da mesma forma que a investigação social precisa ser contextualizada, trabalhar a partir de visões universalizantes e imparciais não seria possível (LAW, 2019). Em lugar disso, os pesquisadores e pesquisadoras são capazes de criar as realidades nas quais suas investigações estão inseridas, pois suas práticas colocam em cena um mundo passível de 
interferência e a partir do qual novos mundos podem ser produzidos (MORAES e ARENDT, 2013).

Nesse sentido, noções como "atores”, “objetos”, “materialidade” e "práticas” tornam-se centrais para a compreensão do emaranhado de varáveis ou elementos que integram as redes de construções de mundos. A sociabilidade dos mundos está construída em conjunto com a materialidade dos objetos (LAW, 2019). Da mesma forma, sua estabilização ou desestabilização estão conectadas às distinções materiais e o social não pode ser compreendido como uma esfera puramente "social" (LAW e MOL, 1995), sendo necessário atentar-se aos contextos de produção das realidades a partir das práticas que as criam.

O mundo torna-se mais complexo com a acepção de que a capacidade de agência, ou seja, a capacidade de participar das situações cotidianas, agir e provocar transformações, afetar trajetórias e tendências, não se restringe aos humanos, ampliando o escopo daquilo que pode ser enquadrado enquanto "ator" (LATOUR, 1994; SOUZA, 2015). Objetos que, até então, existiam apenas enquanto sujeitos da agência humana tornam se detentores de semelhante capacidade de agir, transformar e produzir realidades na mesma medida em que os humanos também são capazes, produzindo tal nível de indeterminação que se torne impossível prever de antemão o que dali poderá emergir (MARRES, 2009; SOUZA, 2015, p. 56).

\subsection{Performando realidades: três distintas performances de água}

Observa-se então que nos desenvolvimentos posteriores a TAR destaca a impossibilidade de conceber a realidade como um dado a priori, mas resultante das práticas, das materialidades e dos processos associativos entre os componentes da rede que a produz, sejam humanos ou não (MOL, 2002, 2008; LAW e MOL, 1995). Resulta disso um convite às ciências sociais para retomar os aspectos práticos da construção da vida cotidiana no momento em que eles formam as realidades (MORAES e ARENDT, 2013). E tanto quanto multiplicam-se as práticas e as materialidades, multiplicam-se mundos, não necessariamente controversos, mas que coexistem (LAW, 2004, 2011; SOUZA, 2015). Isso abre, pois, a possibilidade das ontologias, a saber as condições reais 
de realização com as quais é possível viver e existir no mundo também se tornam múltiplas (LAW e MOL, 1995; MOL, 2008).

A partir desse panorama, se sugere que uma concepção empírica de ontologia (LAW, 2004; MOL, 2008)5 ofereceria mecanismos de entendimento das práticas que permitem performar a água de maneiras múltiplas - considerando-a, ao mesmo tempo, uma categoria híbrida. Na mesma medida, seria na dimensão das práticas que a realidade de um conflito, enquanto limitação ou violação a um direito (FLEURY, 2010), é performada. Semelhante esforço foi realizado no trabalho de Anand (2017), ao analisar como a água é produzida e gerenciada nas cidades em contextos de escassez ou de grandes eventos climáticos. A água, enquanto objeto de análise da autora, integra uma categoria de actante, ou seja, com capacidade de agência, e estabelece realidades distintas a partir das práticas dos humanos ao seu redor. As diferentes reivindicações daqueles que demandam água como um bem público ou como um item a ser precificado são perpassadas pelas práticas cotidianas em torno do abastecimento; performando realidades de uma água que serve para a dessedentação, bem como uma água que atua como um elemento de pertencimento à cidade de Mumbai (ANAND, 2017).

O presente trabalho procura evidenciar os aspectos performáticos que estão em torno do elemento água (ANAND, 2017). O enfoque da análise está voltado para as performances discursivas que criam realidades, agem e transformam práticas em mundo possíveis (LAW e MOL, 2002; NIMMO, 2011). No caso em questão, serão abordadas três performances discursivas distintas, mas que se sobrepõem, através das quais a questão do conflito hídrico pode ser compreendida no contexto de escassez hídrica pelo qual o Distrito Federal passou entre os anos de 2016 e 2018. A primeira delas refere-se à água enquanto práticas econômicas, o que se pode chamar de recurso hídrico. A segunda performance parte do entendimento da água enquanto parte de um discurso científicotecnológico, como um recurso natural. Por fim, a última delas refere-se à água como um elemento necessário à manutenção do bem-estar social; água enquanto direito. Em seguida, as discussões serão direcionadas para aspectos empíricos relativos à análise

\footnotetext{
${ }^{5}$ Em seu trabalho, Annemarie Mol (2008) esclarece que o conceito de "Política Ontológica" é uma criação de John Law (2004). Para referência neste trabalho, entretanto, será utilizado o recorte teóricoconceitual desenvolvido por Mol (2008).
} 
exploratória do período de crise hídrica pelo qual o Distrito Federal passou entre os anos de 2016 e 2018. Todas essas dimensões têm em comum a necessidade de performar uma realidade discursiva bastante específica: de demanda por justiça hídrica que se traduz, ao mesmo tempo, em segurança hídrica (ANAND, 2017).

Primeiramente, as performances discursivas da água enquanto recurso hídrico, ou seja, vinculada às atividades econômicas, sejam elas industriais ou agropecuárias, envolvem argumentos vinculados ao desenvolvimento econômico, à manutenção dos padrões produtivos e dos modos de vida modernos. Os principais questionamentos que envolvem essa performance resumem-se em: de que modo as atividades econômicas podem ser afetadas com a restrição do uso da água? Martín (2015) argumenta que contextos de crise hídrica podem ser vinculados às dinâmicas inflacionárias. Água é, desse modo, articulada como um elemento da cadeia produtiva, na medida em que as condições de vida na Terra, de modo geral, estão a ela vinculadas. O discurso de preocupação com a escassez de água é performado pela impossibilidade da manutenção das atividades econômicas nos mesmos padrões que os utilizados em um período de afluência hídrica. Isso é operacionalizado através das respostas que o mercado poderia dar em um novo contexto de produção, no qual o uso econômico da água seria restringido:

\footnotetext{
Márcio Salvato, coordenador da Graduação em Ciências Econômicas do Ibmec, como os demais especialistas consultados, acredita que o impacto econômico da falta de água vai acabar afetando a economia nacional. "Os índices de inflação ao consumidor irão subir, e é claro que à medida que existe uma expectativa de subida, o Banco Central vai responder a isso com juros elevados, o que vai provocar ainda um maior desaquecimento da economia", afirma o economista (MARTÍN, 2015).
}

O direcionamento para as atividades agrícolas industriais são um dos principais elementos de atribuição de seu valor econômico, pois o entendimento de um recurso a ser explorado, a integra nos mais distintos níveis dos sistemas produtivos. Água é performada como uma commodity, cujos custos crescentes para seu acesso a coloca na centralidade dos conflitos entre distribuidores e consumidores (DUPAS, 2008).

Por outro lado, a água enquanto recurso natural está vinculada a uma arena científica de debate, na qual a ciência e a tecnologia performam discursos a respeito de 
uma realidade na qual ela é vista sob a ótica de seus usos, mecanismos, dinâmicas e fluxos (BLASER, 2019). Ela é performada, nesse caso, como um recurso natural que está se esgotando em razão das falhas humanas ao estabelecer mecanismos efetivos de controle e comunicação com o meio natural. Cabe à agenda científica-tecnológica a responsabilidade de produzir novas ferramentas de comunicação com os fluxos naturais dos ciclos hidrológicos. São práticas do gênero que estabelecem uma performance dos recursos hídricos cuja centralidade é deslocada para o elemento humano.

Essa performance científico-tecnológica da água, em alguma medida, cria uma intersecção com a arena política, pois é frequentemente mobilizada como estratégia de policymaking. $\mathrm{O}$ argumento científico tem potencial de transitar entre as mais distintas realidades que são performadas, mas, na arena da política, há ocasiões em que ambas podem se confundir.

Por fim, a performance da água enquanto direito, mais especificamente enquanto direito humano, é traduzida nas dimensões de seu acesso como um critério de construção de uma sociedade mais justa e sustentável. $\mathrm{O}$ argumento da equidade deixa de lado algumas das recomendações técnicas e se vincula à noção de segurança hídrica, que têm acionado estratégias jurídicas de legitimação de demandas. O princípio do uso prioritário dos recursos hídricos para o consumo humano e a dessedentação de animais (BRASIL, 1997) é uma tradução de demandas que são consideradas legítimas dentro das performances da água.

Água performada enquanto um direito, além de acionar mecanismos jurídicos formais, relaciona-se a elementos sociais estruturantes, considerando-se as dimensões do acesso (ANAND, 2017). Quando a Organização Mundial da Saúde (OMS) publica um relatório que reporta 829.000 mortes por diarreia no ano de 2016, cujas condições de contágio estão intimamente ligadas às condições (ou à ausência) de acesso à água, saneamento e higiene, a performance da água como um direito adquire contornos de interseccionalidade, considerando-se que o maior contingente de mortes se encontra em países do Sul Global, mais especificamente no continente Africano (OMS, 2016). 


\section{As práticas de discurso e os múltiplos mundos: caso da crise hídrica no Distrito Federal}

Para começar a explorar alguns aspectos empíricos do presente trabalho a seção toma como objeto o período de crise hídrica pelo qual o Distrito Federal passou entre os anos de 2016 e 2018. ${ }^{6}$ A metodologia geral desenvolvida está baseada no mapeamento exploratório de conflitos ambientais. Segundo Fuks (1998), a vida política se constitui como uma arena argumentativa, no qual o conflito social é manifestado, assim como os recursos argumentativos mobilizados no desdobramento das dinâmicas de reivindicação. O meio ambiente, enquanto um problema social, define algumas dessas arenas, e os argumentos mobilizados por atores expressam o processo de evolução da agenda de debate (FUKS, 1998).

A montagem do corpo exploratório foi composta, principalmente, por publicações jornalísticas durante o recorte temporal do período de contingenciamento de água. Delimitou-se os conteúdos das plataformas digitais dos jornais Correio Braziliense, Portal Gı e da Empresa Brasileira de Comunicação (EBC). ${ }^{7}$ Buscou-se observar as práticas de discursos pelas quais a água poderia ser performada em um contexto de crise, como o que ocorreu no DF, e em como elas foram veiculadas na mídia.

Utilizando-se da metodologia de análise documental (CRESWELL, 2007), foi feito o levantamento prévio das reportagens nos arquivos dos portais eletrônicos dos periódicos com os termos "racionamento", "crise hídrica" e "Distrito Federal". A partir das reportagens obtidas, foram selecionadas aquelas que possuíssem como palavraschave os termos "conflito", "soluções" e "desigualdade". As análises das reportagens jornalísticas foram feitas a partir da análise de conteúdo dos discursos (CRESWELL,

\footnotetext{
${ }^{6}$ A questão hídrica na região do Distrito Federal, ainda que tenha um histórico mais longo que o período de contingenciamento de água, somente se materializou como uma realidade entre os anos de 2016 e 2018. A despeito do ciclo hídrico da região prever um longo e característico período de estiagem, entre os meses de junho e outubro, no ano de 2016 , a tendência de decréscimo do volume útil das barragens que abastecem o DF não se reverteu iniciado o período de chuvas. Assim, em janeiro de 2017, após o Reservatório da Barragem do Descoberto - o maior reservatório do DF e responsável pelo abastecimento de mais de $50 \%$ da população - alcançar $20 \%$ de sua capacidade, excluindo-se o seu volume morto, a Adasa, amparada pela Resolução no 20, publicada em novembro de 2016 (Adasa, 2016), deu início ao sistema de rodízio no fornecimento de água, que durou até junho de 2018.

${ }^{7}$ A seleção desses três veículos se deveu a sua ampla circulação no Distrito Federal.
} 
2007), verificando-se, principalmente, a ocorrência dos termos "prejuízo", “dependência”, “produção”, “investimento”, “tecnologia”, “fontes de captação”, “desigualdade”, “direito” e “injustiça”.

\subsection{Discurso econômico: recurso hídrico}

Um dos mais proeminentes discursos pelo qual a água foi performada como um recurso componente da cadeia produtiva envolvia a manutenção dos padrões produtivos, frente ao contexto de contingenciamento dos recursos. Nessa performance, a presença de atores ligados ao setor produtivo do Distrito Federal é evidente. Não somente de agentes individuais, como empresários e produtores rurais que aceitaram falar em uma entrevista, mas iniciativas institucionais, como as confederações relacionadas à indústria e institutos ligados ao comércio, que endossam o discurso das perdas e da dependência hídrica como um elemento da cadeia produtiva.

Os discursos veiculados na mídia evidenciam, primeiramente, a dependência da água em duas principais frentes: processos produtivos e manutenção de maquinário e uso dos trabalhadores (IEL, 2018). A partir da dependência, o elemento do prejuízo financeiro alia-se como uma segunda variável no quadro esquemático (MAIA, 2018a). Por fim, vinculados aos discursos de perda e dependência, no contexto de crise pelo qual o Distrito Federal passou, a água também foi performada como um recurso hídrico através de mudanças de práticas de usos, vinculadas a um discurso de adaptação à nova realidade materializada naquelas performances.

Primeiramente, as práticas discursivas recuperadas nos conteúdos jornalísticos se interligam de maneira peculiar, seguindo uma ordem específica de exposição. Primeiramente expõe-se a necessidade e a dependência do recurso para o desenvolvimento da atividade produtiva:

Praticamente metade das 5.530 fábricas instaladas na capital utilizam a água na produção. Dessas, 42,4\% alegam que tiveram a produção prejudicada nas mais diversas escalas, a depender da necessidade do insumo em suas respectivas atividades. [...] das mais de 5 mil plantas industriais do DF, 36o têm sistemas próprios de água - 347 contam com poços artesianos e 13 captam diretamente do rio. As demais recorrem à Companhia de Saneamento Ambiental do DF 
(Caesb). A agência reforça que a liberação para captações e poços depende da disponibilidade hídrica (MAIA, 2018a).

Em seguida, o elemento do prejuízo financeiro compõe o discurso: "A expectativa é que a margem de lucro tenha caído em até 5\%.” (MAIA, 2018a). Não se limitando a expor as perdas financeiras, os agentes salientam os riscos econômicos que envolvem o contingenciamento:

Cerca de 15,3\% alegam perdas financeiras por causa do rodízio. "É um prejuízo a mais em uma indústria que vem de anos difíceis", analisa Jamal Bittar, presidente da Fibra. Ele explica que o impacto só não foi mais significativo por causa do desaquecimento da atividade industrial no DF. "A nossa preocupação é com este ano, em que se observa a melhora na economia e o crescimento na produção", alerta. [...] De 2014 a 2017, o uso de água na indústria reduz drasticamente - passou de 40,9 mil litros anuais por unidade para 26,4 mil litros. O que evidencia o desaquecimento do setor e os prejuízos da falta do insumo (MAIA, 2018a).

O elemento das novas práticas de usos da água articula-se de maneira interessante com alguns discursos de adaptação. A água, ou sua ausência, performa uma realidade que se materializa entre os elementos da produção e do acesso à água (STRANG, 2004):

\footnotetext{
Com um dia da semana sem água, o dono de uma marmoraria no SIA, Carlos Roberto Oliveira Mourão, se adaptou: dobrou o armazenamento, recorre a um caminhão-pipa a cada 15 dias e instituiu o reuso. "Uso o caminhão-pipa porque a água da máquina que corta o mármore não precisa ser potável. Além disso, reaproveito a água da chuva", explica. Roberto Bontempo tem uma fábrica de móveis em Taguatinga Sul. Ele reduziu o consumo em 30\% ao trocar a caixa d'água por outra menor. Além disso, colocou uma garrafa pet nas descargas dos oito banheiros da empresa (MAIA, 2018a).
}

Juntamente aos demais, o elemento discursivo e prático da necessidade de adaptação materializava uma realidade na qual a esfera produtiva da região do Distrito Federal se viu vivenciando. O acesso - ou sua restrição - à água performado nos discursos moldava uma realidade de risco produtivo, que demandava práticas de adaptação e mecanismos. Um dos elementos da produção estava sendo restringido, e algum curso de ação era demandado. 


\subsection{Discurso tecnológico-científico: recurso natural}

Nesse ponto, a performance da água como um recurso natural está contornada por argumentos de aspectos técnicos-científicos que observam seus usos, dinâmicas, fluxos e inter-relações com os demais elementos humanos e não-humanos da cadeia que a compõem. São atores nas performances de discursos toda uma comunidade acadêmica que é colocada como corresponsável para a resolução das dinâmicas de contingenciamento que foram impostas pela escassez da água. Aqui o elemento humano retoma uma série de categorias distintivas de natureza e cultura ao assumir, em suas práticas discursivas, que a escassez hídrica é fruto de uma lacuna na comunicação entre o mundo humano e os fluxos hídricos. Essa dinâmica também pode ser evidenciada nos discursos econômicos, mas o curso de ação que solucionará o problema é demandado, primeiramente, das esferas técnico-científicas.

\footnotetext{
O aumento do consumo, a destruição das nascentes pela impermeabilização do solo, o desmatamento e a poluição, o rebaixamento dos lençóis freáticos e o regime escasso de chuvas contribuem para o cenário pouco esperançoso em 2017. "Com a crise hídrica de 2016, nós, sociedade e governo, avançamos muito na compreensão do ciclo da água. Mas a recuperação dos reservatórios está mais lenta, por isso teremos um 2017 que também vai demandar cuidados e economia", acredita Paulo Salles, presidente da Agência Reguladora de Águas do DF (Adasa) (MAIA, 2018b, grifo da autora).
}

O discurso da interferência humana no meio natural talvez seja o mais proeminente elemento de performance da água como um recurso natural. Enquanto no discurso econômico a água performada como um elemento da cadeia produtiva - assim como o maquinário, a força de trabalho ou a matéria-prima - não distinguia, de forma tão evidente, a separação entre aquilo que cabe ao social e ao ambiental, no discurso científico-tecnológico essa separação se torna cada vez mais evidente.

Com quase $25 \%$ da população vivendo em área irregular e um crescimento populacional de mais 70 mil pessoas por ano, a crise hídrica era uma tragédia anunciada. Somam-se a essa realidade os poucos investimentos feitos ao longo dos anos para diversificar a matriz de captação de água. $O$ principal reservatório da capital federal, a Barragem do Descoberto, tem 42 anos. À época, Brasília contava com pouco mais de 500 mil habitantes. Atualmente, são quase 3 milhões. A última obra de médio porte para captação do recurso foi 
inaugurada em 200o, há 16 anos, no Pipiripau, em Planaltina (MAIA, 2018b, grifo da autora).

O trecho em destaque foi um elemento presente na grande maioria dos registros jornalísticos examinados. A constante demanda por investimentos, por novas tecnologias de captação evidenciava como o discurso científico-tecnológico esteve interseccionado na arena da política e do policymaking, trazendo para o debate mais atores; dessa vez vinculados à esfera político-institucional. É um discurso que transita nas mais distintas realidades, mas que encontra acolhida na arena da política.

Esse discurso, pois, performa a água através de uma lacuna de comunicação entre natureza e cultura. Tal lacuna cria uma situação problemática, na qual demandase da ciência novas pontes e pontos de comunicação que solucionem esse problema. Nesse sentido, a arena da ciência e da política se veem facilmente confundidas.

\subsection{Discurso do bem-estar humano: direito}

Quando performada enquanto um direito humano de manutenção e garantia do bem-estar, a água remete a práticas e discursos que possibilitem a materialização de uma realidade de justiça e segurança hídrica. É comum, nesse ponto, falar-se em processos de "crises", pois diferentes grupos são tocados por essas realidades de maneiras muito distintas. Aqui, as percepções de mundo sobre o que se entende pelo acesso à água são bastante dissemelhantes mesmo dentro de uma mesma performance.

Ampliando um pouco o olhar da análise, em 13 de outubro de 2015, mesma data que, o então governador do Estado de São Paulo, Geraldo Alckmin recebeu um prêmio, em Brasília, por sua gestão à frente da Companhia de Saneamento Básico do Estado (Sabesp) e da Secretaria de Recursos Hídricos (PINHO, 2015), entidades do Terceiro Setor divulgaram um relatório que denunciava à Organização das Nações Unidas (ONU) o que consideravam indícios de violações aos direitos humanos na gestão da crise hídrica no Estado de São Paulo (SOARES, 2015). Na ocasião da divulgação do relatório, Rafael Poço, integrante do secretariado da Aliança pela Água, classificou a premiação como "cinismo institucional": "Isso mostra que temos duas realidades: a de quem está vivendo 
com a falta d'água, com dificuldades e privações, e a realidade de quem acredita no seu próprio discurso" (POÇO, 2015). ${ }^{8}$

A fala de Rafael Poço na ocasião da premiação do então governador Geraldo Alckmin começa a ilustrar como são distintas as realidades sobre o que se entende pela garantia do direito à água e o que seriam violações a esses direitos em um contexto de desabastecimento. Ao mesmo tempo em que, institucionalmente, afirma-se que a gestão da crise hídrica em São Paulo tenha sido um sucesso, são denunciadas violações de direitos:

\begin{abstract}
Em termos quantitativos, a medida que teve maior impacto na diminuição de consumo foi a chamada "redução de pressão" na rede de distribuição de água, medida adotada para toda a Grande São Paulo e que, infelizmente, atinge de forma diferente regiões e segmentos da sociedade. Cidadãos com menor capacidade de reservar água ou distantes dos centros de distribuição, ficam sem água. Essa é uma medida técnica, mas que tem impactos desiguais sobre a população, como apontado em diferentes matérias divulgadas na imprensa, com destaque para matéria do jornal El País que mostra a correlação entre medidas adotadas para diminuir consumo (redução de pressão) e problemas de saúde, como aumento de surtos de diarreia e a epidemia de dengue (ALIANÇA, 2015, p. 16).
\end{abstract}

A realidade do direito ao acesso à água para o bem-estar humano que é performada, no contexto de crise vivenciado no estado de São Paulo, esteve fortemente relacionada a dinâmicas sociais de discriminação, mecanismos estruturantes no Brasil (HERINGER, 2002; VILLACA, 2011). No Distrito Federal, essas dinâmicas tinham um recorte distinto, mas que seguiam uma lógica comum na qual eram múltiplas as realidades de água como um direito fundamental.

Apesar de tanto a Adasa quanto a Caesb terem reforçado a importância do
rodízio, o aposentado José Nonato da Silva está desconfiado. Em sua casa no
Gama, ele afirma que "até quando vai ao banheiro, evita dar descarga para
economizar água". "Se (o corte) for só na casa dos pobres e dos mais
necessitados aí é diferente. Tem que ver se na casa dos deputados e do
pessoal da Caesb também está sendo cortado", alfineta. Pelas redes sociais,
o Governo de Brasília tem recebido muitos questionamentos. Na página oficial
no Facebook, por exemplo, uma postagem relativa ao rodízio recebeu 82
respostas. "Também acho injusto os bairros nobres não terem

\footnotetext{
${ }^{8}$ Ver em: Soares, W. ONGs apontam violações de direitos humanos durante crise hídrica em SP. São Paulo: Portal G1, 2015. Disponível em: <http://g1.globo.com/sao-paulo/noticia/2015/10/ongsapontam-violacoes-de-direitos-humanos-durante-crise-hidrica-em-sp.html> Acesso em o3 de setembro de 2019 .
} 
racionamento. Aqui (em Brasília) não era para faltar água, mas, infelizmente, até hoje não tivermos governo para fazer algo para a parte hídrica", criticou uma usuária (ZAMBON, 2017, grifo da autora).

O trecho acima faz referência ao critério inicial de abrangência do sistema de rodízio, no Distrito Federal. Os instrumentos regulatórios do sistema de racionamento previram, inicialmente, o contingenciamento de água apenas nas regiões administrativas ${ }^{9}$ abastecidas pelo sistema do Reservatório da Barragem do Descoberto o maior do DF e responsável pelo abastecimento de, aproximadamente, $60 \%$ da população. Outros 30\%, abastecidos pelo Sistema Santa Maria/Torto, concentravam os bairros mais nobres da capital, cujo consumo "per capta", a exemplo do Lago Sul, verificado em 2016, era cerca de seis vezes maior do que o consumo em bairros periféricos (DE CASTRO, 2018). O sistema de rodízio só passou a abranger o sistema Santa Maria/Torto após um mês iniciado o rodízio para as regiões abastecidas pelo Descoberto, ainda que contasse com níveis, proporcionalmente, tão baixos quanto o do Descoberto.

Os discursos dos entrevistados refletem a percepção de que realidades distintas de água e crise são vivenciadas. A noção de água como um direito fundamental nessas situações de escassez é profundamente perpassada por interseccionalidades que manifestam essas percepções distintas inclusive no que tocam às noções de bem-estar (LAW e MOL, 2002; ANAND, 2017). Ou seja, às práticas que performatizam as realidades de bem-estar hídrico de um morador do Lago Sul, bairro nobre do Distrito Federal, são distintas das práticas, e realidades através delas performadas, de um morador da Fercal, bairro periférico. E são, pois, contextos de crise e de escassez que tornam mais evidentes essas realidades distintas.

\section{Considerações finais}

A presença da ontologia, de princípio, não implica na busca pela realidade através de práticas epistemológicas, mas como resultado das performances que são

\footnotetext{
9 As regiões administrativas são subdivisões territoriais do Distrito Federal, cujos limites físicos, estabelecidos pelo poder público, definem a jurisdição da ação governamental para fins de descentralização administrativa e coordenação dos serviços públicos de natureza local.
} 
realizadas através dos saberes e dos conhecimentos múltiplos de mundo (MOL, 20o8; LAW e MOL, 2002, 1995). Utiliza-se “ontologias”, no plural, para evidenciar seu aspecto múltiplo. A noção de múltiplas realidades, entretanto, não é um aparato de escolha, mas evidencia momentos de choque, tensão, sobreposição, produção conjunta e intersecção entre as realidades performadas.

Mais especificamente, pensar a água e episódios de estresse hídrico no Brasil, como ocorreu na região Sudeste entre os anos de 2014 e 2016, ou mesmo no Distrito Federal, entre 2016 e primeira metade do ano de 2018, a partir da perspectiva de realidades que são produzidas em torno dos usos da água, evidencia pontos de tensão e as condições nas quais são situados os discursos sobre a água. Observando-se de modo exploratório o contexto recente do Distrito Federal, percebeu-se que os atores humanos que se viam envolvidos na questão - produtores, membros do governo e da comunidade acadêmica, consumidores - mobilizam aparatos discursivos e argumentativos distintos, mas sempre com o intuito comum de legitimar seu interesse em relação ao acesso à água. A água, e a crise, em grande medida, eram performadas através de discursos econômicos, científicos e, inclusive, jurídicos; performava formas de viver e experienciar realidades muito distintas entre si (ANAND, 2017).

Se houvesse uma realidade comum a todos esses atores, a ver, a realidade da crise hídrica, esta seria performada, ao mesmo tempo, pelas noções de escassez, importância estratégica e de responsabilidade ética de todos os atores sociais envolvidos nessa rede. Junto a isso, práticas e discursos múltiplos coexistem em torno da questão, demonstrado que ontologias - no plural - se constroem nesses momentos de exercício das práticas cotidianas locais, multiplicando as realidades ao mesmo tempo (SOUZA, 2015).

Desse modo, ainda que as performances de determinadas práticas adquiram certa homogeneidade, como ocorre no caso da água enquanto um direito, quando vinculada às noções de bem-estar nota-se pontos de conflito e de estranhamento frente a fatores outros que não apenas a realidade da crise (MOL e LAW, 2002). Nesse ponto, há o choque entre ontologias dentro de uma mesma realidade. O que não implica que o choque e a tensão sejam constantes, uma vez que realidades tão distintas se sobrepõem. Significa dizer que existem e cristalizam-se em coexistem (SOUZA, 2015). A fluidez das 
posições é recuperada a partir do momento em que se torna necessário reconhecer de quais arranjos, ou de quais realidades falam os atores. A despeito de falar em "água", multiplicam-se os mundos e os entendimentos que circundam a questão.

\section{Referências}

AGÊNCIA REGULADORA DE ÁGUAS, ENERGIA E SANEAMENTO DO DISTRITO FEDERAL (Adasa) (Brasília, DF). Distrito Federal. Resolução normativa no 20, de o7 de novembro de 2016. Resolução normativa no 2o, Brasília, DF, 7 nov. 2016. Disponível em:

http://www.adasa.df.gov.br/images/pdf/Resolucao20_2016_DeclaraEstadodeRestricaoe RegimedeRacionamento.pdf. Acesso em: 4 set. 2019.

ALCADIPANI, Rafael; TURETA, César. Teoria ator-rede e análise organizacional: Contribuições e possibilidades de pesquisa no Brasil. Organizações e Sociedade, Salvador, v. 16, n. 51, p. 647-664, Out-Dez 2009. Disponível em: https://www.scielo.br/scielo.php?pid=S1984-

92302009000400003\&script=sci_abstract\&tlng=pt. Acesso em: 7 dez. 2020.

ALIANÇA pela Água. Crise hídrica e direitos humanos: Relatório sobre violações de direitos humanos na gestão hídrica no estado de São Paulo (versão completa). São Paulo: Coletivo de Luta pela Água, outubro de 2015. Disponível em: https://www.aliancapelaagua.com.br/wp-content/uploads/2016/10/relatorio-direitoshumanos-completo-2016.pdf. Acesso em: 5 jun. 2019.

ANAND, Nikhil. Hydraulic city: water and the infrastructures of citizenship in Mumbai. Durham e Londres: Duke University Press, 2017.

BARNES, Barry; BLOOR, David; HENRY, John. Scientific Knowledge: a sociological analysis. Chicago: The University of Chicago Press, 1996.

BLASER, Mario. On the properly political (disposition for the) Anthropocene. Anthropological Theory, [s. 1.], v. 19, n. 1, p. 74-94, 2019. Disponível em: https://journals.sagepub.com/doi/abs/10.1177/1463499618779745. Acesso em: 13 maio 2019.

BLOOR, David. Programa Forte na Sociologia do Conhecimento. In: CONHECIMENTO e imaginário social. São Paulo: Editora UNESP, 1976/2009. cap. 1, p. $15-44$.

BRASIL. Lei no 9.433, de 8 de janeiro de 1997. Política Nacional de Recursos Hídricos, Brasília, DF: Diário Oficial da União, 8 jan. 1997. Disponível em: http://www.planalto.gov.br/ccivil_o3/leis/l9433.htm. Acesso em: 5 mai 2019. 
AGÊNCIA NACIONAL DE ÁGUAS (ANA). Programa Produtor de Água (Nota informativa). Brasília, DF, agosto de 2018. Disponível em: https://www.ana.gov.br/todos-os-documentos-do-portal/documentos-sip/produtorde-agua/documentos-relacionados/1-nota-informativa-programa-produtor-deagua.pdf. Acesso em: 5 mai 2019.

CALLON, Michel. Some elements of a sociology of translation: domestication of the scallops and the fishermen of St Brieuc Bay. In: LAW, John (org.). Power, action and belief: A new sociology of knowledge. Londres: Routledge, 1986. p. 196-233.

DE CASTRO, Kássia Batista. Consumo de água do Distrito Federal por Região Administrativa. Brasília: Companhia de Planejamento do Distrito Federal (Codeplan), 2018. $36 \quad$ p. Disponível em: http://www.codeplan.df.gov.br/wpcontent/uploads/2018/o2/TD-50-Consumo-de-\%C3\%81gua-do-Distrito-Federal-porRegi\%C3\%A3o-Administrativa.pdf. Acesso em: 4 set. 2019.

COLLINS, Harry. Mudando a ordem: replicação e indução na prática científica. Belo Horizonte: Fabrefactum, 1985/2011.

CORTE, Thaís Dalla. A (re)definição do direito à água no século XXI: perspectiva sob os enfoques da justiça e da governança ambiental. 2015. 612 f. Dissertação (Mestrado em Direito) - Universidade Federal de Santa Catarina, Centro de Ciências Jurídicas, Programa de Pós-Graduação em Direito, Florianópolis, 2015. Disponível em: https://repositorio.ufsc.br/xmlui/handle/123456789/133225. Acesso em: 4 set. 2019.

CRESWELL, John W. Qualitative and research design: Choosing among five approaches. 2. ed. Thousand Oaks: Sage, 2007.

DUARTE, Tiago Ribeiro. Émile Durkheim e o Programa Forte em Sociologia do Conhecimento: Duas perspectivas sobre as relações entre conhecimento científico, realidade empírica e sociedade. Teoria e Sociedade, v. 14, n. 2, p. 26-51, 2007.

; REYES-GALINDO, Luís. Estudos Sociais das Ciências e Tecnologias. Revista Brasiliense de Pós-Graduação em Ciências Sociais (Pós), Brasília, v. 14, n. 2, p. 11-33, agosto 2019. Disponível em: https://periodicos.unb.br/index.php/revistapos/issue/download/1754/343. Acesso em: 20 set. 2019.

DUPAS, Gilberto (org.). Meio ambiente e crescimento econômico: Tensões estruturais. São Paulo: UNESP, 2008. 304 p. ISBN 9788571398658.

DURKHEIM, Émile. As formas elementares da vida religiosa. In: CIVITA, Victor (ed.). Os pensadores: XXXIII. 1. ed. São Paulo: Abril cultural, 1973. p. 505-547. 
FLEURY, Lorena C. Conflitos ambientais: uma proposta de bases teóricas para a discussão. In: ENCONTRO NACIONAL DA ASSOCIAÇÃO NACIONAL DE PÓSGRADUAÇÃO E PESQUISA EM AMBIENTE E SOCIEDADE (ANPPAS), V., 2010,

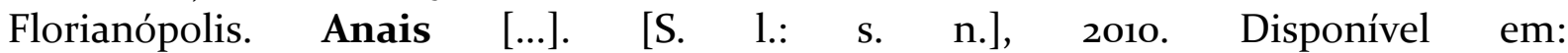
http://www.anppas.org.br/encontro5/cd/artigos/GT2-829-954-20100904002905.pdf.

Acesso em: 20 abr. 2019.

FLICK, Uwe. Designing qualitative research. Thousand Oaks: Sage, 2007.

FUKS, Mario. Arenas de ação e debate públicos: conflitos ambientais e a emergência do meio ambiente enquanto problema social no Rio de Janeiro. Dados, Rio de Janeiro, v. 41, n. 1, p. 87-113, 7 jan. 2021. Disponível em: https://www.scielo.br/scielo.php?script=sci_arttext\&pid=Soo11-52581998000100003.

Acesso em: 4 set. 2019.

HARAWAY, Donna. Saberes localizados: a questão da ciência para o feminismo e o privilégio da perspectiva parcial. Cadernos Pagu, Campinas, v. 5, n. 5, p. 7-41, 1995. Disponível

em: https://periodicos.sbu.unicamp.br/ojs/index.php/cadpagu/article/view/1773. Acesso em: 5 set. 2019 .

HARDING, Sandra. Feminism and methodology. Bloomington: Indiana University Press, 1987.

HERINGER, Rosana. Desigualdades raciais no Brasil: síntese de indicadores e desafios no campo das políticas públicas. Cadernos de Saúde Pública, Rio de Janeiro, v. 18, n. suppl, p. S57-S65, 2002. Disponível em: https://www.scielo.br/pdf/csp/v18so/13793.pdf. Acesso em: 9 dez. 2020.

IEL. Pesquisa Impacto do Racionamento de Água na Indústria do DF. Brasília: Núcleo de Estudos e Pesquisas do Instituto Euvaldo Lodi (IEL-DF), 2018. Disponível em: <https://www.sistemafibra.org.br/iel/component/edocman/pesquisa-impacto-doracionamento-de-agua-na-industria-do-distrito-federal> Acesso em: o3 set. 2019.

JENSEN, Carl B. A nonhumanist disposition: on performativity, practical ontology, and intervention. Configurations, [s. 1.], v. 12, n. 2, p. 229-261, 2004. Disponível em: https://www.researchgate.net/publication/236724091_A_Nonhumanist_Disposition_O n_Performativity_Practical_Ontology_and_Intervention. Acesso em: 3 dez. 2020.

KNORR-CETINA, Karin D. Scientific Communities or Transepistemic Arenas of Research?: a critique of quasi-economic models of science. Social Studies of Science, [s. 1.], v. 12, n. 1, p. 101-130, 1982. Disponível em: https://journals.sagepub.com/doi/10.1177/030631282012001005. Acesso em: 15 jun. 2019.

LATOUR, B. Jamais formos modernos: Ensaio de antropologia simétrica. São Paulo: Editora 34, 1994. 
; WOOLGAR, Steve. A vida de laboratório: a produção dos fatos científicos. Rio de Janeiro: Relume Dumará, 1997.

LAW, John. Notes on the theory of the actor-network: ordering, strategy, and heterogeneity. Systems pratice, [s. 1.], v. 5, n. 4, p. 379-393, 1992. Disponível em: https://link.springer.com/article/10.1007/BFo1059830. Acesso em: 20 maio 2019.

After Method: Mess in Social Science Research. Oxford and New York: Routledge, 2004.

Colateral realities. In: DOMINGUEZ RUBIO, F; BAERT, P (ed.). The politics of knowledge. Londres: Routledge, 2009. p. 156-178. Disponível em: http://www.heterogeneities.net/publications/Law2009CollateralRealities.pdf. Acesso em: 15 fev. 2020. __ Material semiotics. 2019. Disponível em: $<$ http://w.heterogeneities.net/publications/Law2019MaterialSemiotics.pdf > Acesso em o4 de dezembro de 2020.

; MOL, Annemarie. Local entanglements or utopian moves: an inquiry into train accidents. The Sociological Review, [s. 1.], v. 50, n. 1, p. 82-105, 2002. Disponível em: https://journals.sagepub.com/doi/10.1111/j.1467-954X.2002.tbo3580.x. Acesso em: 4 dez. 2020.

. Notes on materiality and sociality. The Sociological Review, [s. 1.], v. 24, p. 274294, 1995. Disponível em: https://journals.sagepub.com/doi/10.1111/j.1467954X.1995.tboo6o4.x. Acesso em: 5 dez. 2020.

MAIA, Flávia. Indústria busca solução contra a crise hídrica no Distrito Federal. Correio Braziliense [On-line], Brasília, 21 fev. 2018. Cidades, p. 1-1. Disponível em: https://www.correiobraziliense.com.br/app/noticia/cidades/2018/o2/21/interna_cidade sdf,661158/industria-busca-solucao-contra-a-crise-hidrica-no-distrito-federal.shtml.

Acesso em: 3 set. 2019.

. Níveis críticos ameaçam o abastecimento e conflitos pela água são realidade no DF. Correio Braziliense [On-line], Brasília, 23 jan. 2018. Especial, p. 1-1. Disponível em: http://especiais.correiobraziliense.com.br/niveis-criticos-ameacam-o-abastecimento-econflitos-pela-agua-sao-realidade-no-df. Acesso em: 1 set. 2019.

MARRES, Noortje. Testing powers of engagement: green living experiments, the ontological turn and the undoability of involvement. European Journal of Social Theory, [s. 1.], v. 12, n. 1 , p. 117-133, 2009. Disponível em: https://journals.sagepub.com/doi/10.1177/1368431008099647. Acesso em: 7 dez. 2020.

MARTIN, María. Efeito dominó da seca afetará toda a economia, começando pela alface. El País [On-line], São Paulo, 28 jan. 2015. Crise Hídrica, p. 1-1. Disponível em: 
https://brasil.elpais.com/brasil/2015/o1/28/economia/1422463421_541248.html. Acesso em: 8 jul. 2019.

MERTON, Robert K. Sociologia: Teoria e Estrutura. São Paulo: Mestre Jou, 1968.

MOL, A. Política ontológica: Algumas ideias e várias perguntas. In: Nunes, J. A. e Roque, R. (orgs.) Objectos impuros. Experiências em estudos sociais da ciência. Porto: Edições Afrontamento, 2008. Disponível em: https://www.who.int/gho/phe/water_sanitation/burden/en/. Acesso em 11 de julho de 2019.

The Body Multiple: Ontology in Medical Practice. Durham and London: Duke University Press, 2002.

MORAES, Marcia Oliveira; ARENDT, Ronald João Jacques. Contribuições das investigações de Annemarie Mol para a psicologia social. Psicologia em estudo, Maringá, v. 18, n. 2, p. 313-321, 2013. Disponível em: http://www.scielo.br/scielo.php?script=sci_arttext\&pid=S1413-73722013000200012.

Acesso em: 6 dez. 2020.

NIMMO, Richie. Actor-network theory and methodology: social research in a morethan-human world. Methodological Innovations, [s. 1.], v. 6, n. 3, p. 108-119, 2011. Disponível em: https://journals.sagepub.com/doi/10.4256/mio.2011.o10. Acesso em: 9 dez. 2020.

ORGANIZAÇÃO MUNDIAL DA SAÚDE (OMS). Global Health Observatory (GHO) data. In: Mortality and burden of disease from water and sanitation. [S. 1.], 2016. Disponível em: https://www.who.int/gho/phe/water_sanitation/burden_text/en/. Acesso em: 3 jun. 2019.

PINHO, Márcio. Alckmin diz que prêmio sobre gestão hídrica é 'modéstia à parte, merecido'. Portal G1 [On-line], São Paulo, 23 set. 2015. São Paulo, p. 1-1. Disponível em: http:/g1.globo.com/sao-paulo/noticia/2015/o9/alckmin-diz-que-premio-sobre-gestaohidrica-e-modestia-parte-merecido.html. Acesso em: 3 set. 2019.

PREMEBIDA, Adriano; NEVES, Fabrício Monteiro; ALMEIDA, Jalcione. Estudos sociais em ciência e tecnologia e suas distintas abordagens. Sociologias, Porto Alegre, ano 13, n. 26, p. 22-42, 2011. Disponível em: https://www.scielo.br/pdf/soc/v13n26/o3.pdf. Acesso em: 10 dez. 2020.

RALLIS, Sharon; ROSSMAN, Gretchen. An introduction to qualitative research: learning in the field. Thousand Oaks: Sage, 2017.

SANTOS, Sinval Neves. O compartilhamento das águas transfronteiriças superficiais. In: ENCONTRO ANUAL DA ASSOCIAÇÃO NACIONAL DE PÓS-GRADUAÇÃO E PESQUISA EM AMBIENTE E SOCIEDADE (ANPPAS), II., 2004, Indaiatuba, SP. Anais 
[...]. $\quad[$ S. $\quad 1 .: \quad$ s. $\quad$ n.], 2004. Disponível em: http://www.anppas.org.br/encontro_anual/encontro2/GT/GT13/sinval_neves.pdf. Acesso em: 9 jul. 2019.

SCHIEBINGER, Londa. O feminismo mudou a ciência? Bauru: EDUSC, 2001.

SHAPIN, Steve. The politics of observation: cerebral anatomy and social interests in the Edinburgh phrenology dispute. The Sociological Review, [s. 1.], v. 27, n. 1, p. 139-178, 1979. Disponível em: https://scholar.harvard.edu/files/shapin/files/shapinpolitics_of_observation_1979.pdf. Acesso em: 11 jul. 2019.

SOARES, Will. ONGs apontam violações de direitos humanos durante crise hídrica em SP. Portal Gı [On-line], São Paulo, 14 out. 2015. São Paulo, p. 1-1. Disponível em: http:/g1.globo.com/sao-paulo/noticia/2015/10/ongs-apontam-violacoes-de-direitoshumanos-durante-crise-hidrica-em-sp.html. Acesso em: 11 jul. 2019.

SOUZA, Iara Maria de Almeida. A noção de ontologias múltiplas e suas consequências políticas. Ilha - Revista de Antropologia, Florianópolis, v. 17, n. 2, p. 49-73, 2015. Disponível em: https://periodicos.ufsc.br/index.php/ilha/article/view/21758034.2015V17n2p49. Acesso em: 2 dez. 2020.

STRANG, Veronica. The Meaning of Water. Oxford e Nova Iorque: Berg, 2004.

TRAWEEK, Sharon. Beamtimes and lifetimes: the world of high-energy physicists. Cambridge e Massachusetts: Harvard University Press, 1988.

VILLACA, Flávio. São Paulo: segregação urbana e desigualdade. Estudos Avançados: [On-line], São Paulo, v. 25, n. 71, p. 37-58, 2011. Disponível em: https://www.scielo.br/pdf/ea/v25n71/o4.pdf. Acesso em: 10 dez. 2020.

ZAMBON, Eric. Chuva de reclamações nas regiões afetadas pela crise hídrica no DF. Jornal de Brasília [On-line], Brasília, 19 jan. 2017. Cidades, p. 1-1. Disponível em: https://jornaldebrasilia.com.br/cidades/chuva-de-reclamacoes-nas-regioes-afetadaspela-crise-hidrica-no-df/. Acesso em: 3 jul. 2019. 